\title{
Corrigendum: Cerebral Cavernous Malformations: Review of the Genetic and Protein-Protein Interactions Resulting in Disease Pathogenesis
}

\author{
Jacob F. Baranoski, M. Yashar S. Kalani, Colin J. Przybylowski and Joseph M. Zabramski*
}

Department of Neurosurgery, St. Joseph's Hospital and Medical Center, Barrow Neurological Institute, Phoenix, AZ, United States

Keywords: cavernous malformation, CCM, CCM1, CCM2, CCM3, KRIT1, PDCD10

\section{A corrigendum on}

Cerebral Cavernous Malformations: Review of the Genetic and Protein-Protein Interactions Resulting in Disease Pathogenesis

by Baranoski JF, Kalani MYS, Przybylowski CJ, Zabramski JM. Front Surg (2016) 3:60. doi: 10.3389/ fsurg.2016.00060

In the original article, the reference Cigoli et al. is missing from the section "Additional Developments", sub-section "PDCD10 Mutations Associated with Increased CCM Severity".

The text of the subsection should read:

Although loss-of-function mutations in any of the three CCM genes may result in CCM formation, different mutations result in varying degrees of disease severity. Patients with CCMs harboring PDCD10 mutations have a significantly greater disease burden and severity compared to those with KRIT1 or CCM2 mutations. Cigoli et al. found that patients with PDCD10 mutations had an earlier onset of disease symptomology compared to those with KRIT1 or CCM2 mutations (50). Shenkar et al. demonstrated that patients with familial PDCD10 mutations had a significantly more aggressive clinical CCM disease phenotype than patients with KRIT1 or CCM2 familial disease or sporadic lesions (44). Patients with PDCD10 mutations had an increased number of lesions and also presented with lesion hemorrhages earlier in life. Moreover, in addition to the CCMs, these authors found PDCD10 aberrations, including scoliosis, cognitive disability, and skin lesions, further suggesting that PDCD10 plays other roles in tissue development aside from endothelial cell formation $(43,44)$.

The authors apologize for this error and state that this oversight does not change the scientific conclusions of the article in any way.

Received: 06 March 2017

Accepted: 22 May 2017

Published: 18 July 2017

Citation:

Baranoski JF, Kalani MYS, Przybylowski CJ and Zabramski JM

(2017) Corrigendum: Cerebral Cavernous Malformations: Review of the Genetic and Protein-Protein Interactions Resulting in Disease Pathogenesis.

Front. Surg. 4:31.

doi: 10.3389/fsurg.2017.00031

\section{REFERENCE}

50. Cigoli MS, Avemaria F, De Benedetti S, Gesu GP, Accorsi LG, Parmigiani S, et al. PDCD10 gene mutations in multiple cerebral cavernous malformations. PLoS One (2014) 9:e110438. doi:10.1371/journal.pone.0110438

Conflict of Interest Statement: The authors declare that the research was conducted in the absence of any commercial or financial relationships that could be construed as a potential conflict of interest.

Copyright ( $\odot 2017$ Baranoski, Kalani, Przybylowski and Zabramski. This is an open-access article distributed under the terms of the Creative Commons Attribution License (CC BY). The use, distribution or reproduction in other forums is permitted, provided the original author(s) or licensor are credited and that the original publication in this journal is cited, in accordance with accepted academic practice. No use, distribution or reproduction is permitted which does not comply with these terms. 